\title{
Pre-Service Elementary School Teachers Becoming Mathematics Teachers: Their Participation in an Online Professional Community
}

\author{
Annie Savard ${ }^{1}$, Terry Wan Jung $\operatorname{Lin}^{2} \&$ Natasha Lamb \\ ${ }^{1}$ Faculty of Education, McGill University, Montréal, Canada \\ ${ }^{2}$ Faculty of Education, University of Alberta, Edmonton, Canada \\ ${ }^{3}$ Ottawa-Carleton District School Board, Ottawa, Canada \\ Correspondence: Annie Savard, Faculty of Education, McGill University, Montréal, Québec, H3A 1Y2 Canada. \\ E-mail: annie.savard@mcgill.ca
}

Received: August 8, 2016

Accepted: September 20, $2016 \quad$ Online Published: November 8, 2016

doi:10.5539/jel.v6n1p41

URL: http://dx.doi.org/10.5539/jel.v6n1p41

\begin{abstract}
This pilot study sought to examine the mathematical knowledge for teaching that pre-service teachers used when participating in an online community, and to gain insight into their epistemological stance. The participants of this study were among the pre-service teachers in a large urban university, chosen as they were completing their mathematics methods course in their teacher-education program and before entering a field experience in the same academic year. A qualitative analysis of the online discussions of our participants was done using Ball and her colleagues' (2008) framework for mathematical knowledge for teaching and that of communities of practice (Wenger, 1998). These theories provided insight into the development of pre-service teachers as they moved from "student" to "teacher". Our findings show that pre-service teachers struggle to shed their student-perspective as they transition from theory to practice. This was readily evident in how they used their mathematical knowledge for teaching in their online exchange. Our work contributes to understanding the complexity of becoming a mathematics teacher in elementary school.
\end{abstract}

Keywords: pre-service elementary school teachers, online professional community, mathematical knowledge for teaching, mathematics, epistemological stances

\section{Introduction}

"Mathematics teacher education is highlighted by its complexities and challenges, particularly when the goal is to prepare prospective teachers and to help practicing teachers to teach in the ways that they did not experience as learners of mathematics" (Olive Chapman, 2012).

The knowledge required to teach mathematics is complex. Ball, Hill, and Bass (2005) have pointed to the intricate nature of mathematical knowledge for teaching, showing that mastery of both pedagogical and subject knowledge is necessary to teach mathematics. Development of both types of knowledge should be done in tandem with both subject and pedagogical knowledge given equal emphasis. Furthermore, developing mathematical knowledge for teaching should also include practical classroom experience.

This pilot study was conducted in such a practical setting. An online professional community was developed so that pre-service teachers could dialogue with each other while engaging in their respective field experiences. Our main research question was: what mathematical knowledge for teaching emerged in novice elementary teachers' discussions as they participated in an online professional community during their field experience? Our intention was to analyze the discussion threads for evidence of the novices' mathematical knowledge for teaching as they developed the epistemological stance of an elementary-school mathematics teacher. The focus on a field experience allowed the pre-service teachers to apply their knowledge in a teaching setting, while the online community allowed for the researchers to examine dialogue related to teaching and learning how to teach. What was revealed was the unique position of pre-service teachers, and how their dual position of student and teacher plays an important role in what knowledge for teaching is predominantly mobilized when they discuss with each other. 


\section{Training Teachers as Professionals}

In order to understand how pre-service teachers develop a collective knowledge base when working together, and what the nature of that knowledge base might be, one must understand what we mean by knowledge for teaching and how that knowledge is developed and identified in the context of collaborative learning.

Lee Shulman (1987) first proposed the idea that teachers have a specific knowledge base that is more than just knowledge of subject matter. Teachers need to understand Specialized Content Knowledge (SCK) in more specific contexts. Specifically, teachers require knowledge of the programs and materials used to teach a subject (curriculum knowledge), in combination with Pedagogical Content Knowledge (PCK), which is an intricate combination of both subject knowledge and knowledge of pedagogy. In other words, Shulman suggested that the teaching of some subject requires a high-level of knowledge that goes far beyond knowledge of the subject alone.

More recently, Ball, Thames, and Phelps (2008) extended our understanding of the knowledge required for teaching by specifically focusing on the teaching of mathematics. In the broadest sense, Ball and her colleagues argued that mathematical knowledge for teaching is comprised of two main domains: knowledge used in the context of working with students and knowledge not used in this context. The knowledge a teacher utilizes in the context of working with students further elaborates Shulman's PCK into three different areas: Knowledge of Content and Students (KCS), Knowledge of Content and Teaching (KCT) and Knowledge of Content and Curriculum (KCC) (Ball et al., 2005). We understand knowledge of content and students to be knowledge of mathematics as it links with knowledge of how students "think about, know and learn" mathematics (Hill, Ball, \& Schilling, 2008, p. 375). Similarly, knowledge of content and teaching is knowledge of mathematics as it links to teaching mathematics; also, knowledge of content and curriculum is similar to Shulman's curricular knowledge or knowledge of the mathematical programs and materials used to teach mathematics (Hill et al., 2008). What Ball et al. (2008) classified as knowledge a teacher utilizes in contexts that do not involve students refines Shulman's subject matter knowledge specific to mathematics. In this category, Ball et al. (2008) distinguished three aspects of Subject Matter Knowledge (SMK) of mathematics: specialized content knowledge, common content knowledge and knowledge at the mathematical horizon. Specialized Content Knowledge (SCK) is the mathematical knowledge that is specifically utilized by a teacher to engage in particular teaching tasks. Common Content Knowledge (CCK), on the other hand, is the mathematical knowledge used in teaching but shared with other professions that use mathematics. Knowledge at the mathematical horizon can be considered knowledge of how mathematical ideas and concepts link to other mathematical ideas in the past and future of a student's learning trajectory (Hill et al., 2008).

It has been argued that a close link to teacher practice is necessary in order to develop adequate mathematical knowledge for teaching (Hiebert, Gallimore, \& Stigler, 2002). The complex nature of mathematical knowledge for teaching and the need to make meaningful connections to practice complicates the recognition and analysis of knowledge development. By examining how individuals interact with one another, the vehicle in which mathematical knowledge for teaching is developed can be better understood. Wenger's (1998) community of practice offers an appropriate framework to examine the elements that enable the acquisition and development of mathematical knowledge for teaching.

A community of practice is understood to be a space where learning takes place and furthermore, where learning is the practice itself. Such communities of practice involve the evolution of three interconnected pieces. First, the membership of the community is defined by both a shared interest and an implied competency from each individual within that interest which creates what Wenger (1998) qualified as mutual engagement. This competency provides a means in which members can engage in the community both thoughtfully and meaningfully. Together, the members find ways in which to engage and interact with each other. Second, as they navigate their way through the functionality of their collaborations, members of the community also make sense and meaning of their situation and their collective existence within their practice. They develop a joint enterprise (Wenger, 1998). In other words, as the community evolves, so does the way in which the members of the community understand their practice and work, developing a means to respond to the context in which they find themselves. So, the means of participation within the community, the sharing of information or engagement in activities, is determined by the members themselves and allows individual members of the community to not only learn from one another but also to understand their collective being. Third, as this process evolves, so does the natural development of a repertoire of tools, artifacts and/or routines that provide a way for community members to share knowledge and learning within their practice. This process is what Wenger (1998) identified as a shared repertoire. The community develops a means to preserve their practice and what is learned in order to 
allow both existing members and new members to understand the idiosyncrasies of the community. In this project, students participating in a virtual community developed a mutual engagement in this setting and their interactions were examples of their collective enterprise in supporting each other during their field experience.

Pre-service teachers bring unique perspectives to their work as a result of the transitional phase they find themselves in. In the literature, we can find a large body of research studies on pre-service teachers' beliefs and perceptions on teaching and learning, as well as how those preconceptions influence their classroom practices (Charalambos, Philippou, \& Kyriakides, 2002; Cooney, Shealy, \& Arvold, 1998; Ernest, 2000). These perceptions and preconceptions are often linked to the pre-service teachers' epistemological beliefs (Hofer \& Pintrich, 1997; Schommer, 1994) or toward mathematical knowledge (Savard, 2014). In this paper, we used the concept of changing epistemological stance as described by DeBlois and Squalli (2002) to examine novice teachers' perception and application of knowledge. DeBlois and Squalli studied 160 novice teachers' interpretations of children's thinking, as well as their proposed interventions with those children. Theses authors considered pre-service teachers' as complex epistemological beings. This complexity, they argued, arises as a result of the interplay between three epistemological positions: that of a former mathematics student, that of a university student in a teacher education program, and that of a teacher. From the perception of a former student, pre-service teachers' conceptions about being a teacher are based on their own mathematics learning experiences, whether negative or positive. As university students in a teacher-education program, pre-service teachers past experiences conflict between their existing knowledge of mathematics and their understanding of the effects of this knowledge on how they will teach mathematics. Thus, this stance as university student is seen as a position that bridges the gap between the conceptions formed as a student (in elementary school) and the conceptions developed as a prospective teacher (Brown et al., 1999; DeBlois \& Squalli, 2002). Finally, pre-service teachers take on the role of teacher when they are in the classroom during their field experience, preoccupied with both students' learning and with the teaching of mathematics.

In this study, we sought answers to the following questions: a) what mathematical knowledge for teaching emerged in novice elementary teachers' discussions as they participated in an online professional community during their field experience and $b$ ) which epistemological stance might be highlighted by this knowledge?

\section{Methodology}

\subsection{Data Collection}

Data collection was done during participants' field experience in the second year of a four-year teaching program for elementary school teachers (K-6) at an urban university in Canada. This program had two mandatory mathematics pedagogy courses and one optional mathematics course, along with pedagogy courses in other subject areas. This particular cohort of novice teachers was chosen because the field experience took place in the three weeks following completion of their second and last mathematics pedagogy course in the winter semester of this particular program. During the fieldwork placement, the novice teachers were mentored by Cooperating Teachers (CT) and were expected to teach in classrooms. Additionally, pre-service teachers attended a weekly seminar course during their three-week field experience.

The data set comes from discussions that took place within an online community. The online space utilized the WebCT Vista platform. This platform was chosen over other web-based platforms (e.g., Yahoo groups) to address any privacy and ethical issues. Furthermore, this platform was familiar to the participant-pool, as it is widely used at this particular urban university. This served to alleviate any technical difficulties in learning a new technology. As the participants' field experience was only three-weeks in duration, it was desirable to ensure the online space was as easy to use as possible (Hough et al., 2004). Since the university used this platform for course administration, the design elements available were limited to those defined by the university. In particular, discussion threads were used to set up topics of discussion that were thought to be of relevance to this group of pre-service teachers. These topics included "Introduction", "Mathematics Questions", "About Teaching", and "Random". In addition, a journal space, "Share" was set up for individuals to share resources they had developed, and a blog space, "Open Mic" was set up so individuals could share accounts of their day or simply keep a "journal" of their day to share with others. There was also a section in which one could share websites that contained relevant or interesting material. In creating this particular section, we had included some notable mathematics websites with useful resources for any teacher of mathematics. It was important that the participants had a feeling of ownership over this space. Therefore, we created a "Suggestion Box" discussion, in which comments and suggestions for how to improve the space were invited.

One of the researchers played the role of the moderator (NL) and, after a few days of little activity from the participants, responded to some questions. Participants chose their own pseudonyms for use in the online forum 
and did not know the identities of others writing with their chosen pseudonyms. We wanted participants to feel free to ask questions; even those that may feel embarrassed to ask. We also wanted to ensure we could not recognize the identities of the collaborative teachers and schools affiliated with pre-service teachers through their field placements. In order to give participants an opportunity to become familiarized with the space, as well as to provide feedback and suggestions as to how they wanted the space to look, the online community opened three weeks prior to the beginning of the field experience. This was done in the hope of providing participants with some feeling of ownership over the environment (Schlager, Fusco, \& Schank, 1998). The general use of the space and, in particular, the online discussions served as the main data source for this study.

The mathematics pedagogy course served as a venue through which pre-service teachers began to talk about teaching mathematics. Our goal was to create a tool through which students could connect with each other while dispersed throughout a large city during their field experience. Thus, giving those individuals who agreed to be a part of the study $(\mathrm{N}=23)$ access to an online community provided them with a means to continue their in-class discussions while in their field experience. Consenting participants were given access to a closed, private, web-based community that facilitated the sharing of files and web links, and supported an asynchronous-learning discussion forum. Participants were asked to post their own questions and answer each other's questions, as well. Participants were free to post comments or to respond, and there was no obligation to contribute to the discussion.

Over the course of six weeks, 23 participants logged-in to the online space and there were ninety-nine login sessions in total. Although participants were provided with access information (user names and passwords) three weeks prior to the start of their field experience, the level of participation and general activity in the online discussion forum was most active in the first two weeks of the field experience. Each participant's participation varied in terms of both the number of contributions made and the number of logins. Eight participants logged-in one time each and made no contributions to any of the discussions. Two participants logged-in twice early in the field experience and both contributed just one item in one of the discussion threads. There were three participants that logged into the online space on multiple occasions throughout the field experience but who did not contribute to any of the discussions. In addition, four participants followed a similar pattern in that they logged-in on multiple occasions throughout the field experience and contributed to just one discussion thread. Contributions from these four individuals were made merely to introduce themselves, and they did not engage in any discussions related to teaching or to mathematics. The core of the online discussions was between six participants who were engaged with the online space throughout their field experience. Five of these six participants logged-in regularly, posed questions to the group, and provided their opinion or feedback to the online discussions. The sixth participant logged in just twice, about three weeks apart, but read all the previous discussions and contributed to each of the thread. The relatively low number of active participants in the online discussion can be attributed to a number of factors. Some participants experienced technical difficulties that prevented them from successfully logging-in. As it was not possible to coordinate a meeting to resolve these issues in person, the participants were given the contact information of the university's technical help desk. The added task of seeking assistance from the help desk may have caused some individuals to self-withdraw from the study. Others revealed in the online discussion that they did not have the opportunity to teach mathematics in their field experience, which was due to the expectation that pre-service teachers follow their cooperating teacher's timetable.

\subsection{Data Analysis}

The analysis of the online discourse was approached using the methods of a content analysis (Strauss \& Corbin, 1998) as a guide. The process of combing through the data began with open coding, the process of "opening up the text and exposing the thoughts, ideas and meaning contained therein in order to uncover, name and develop concepts" (Strauss \& Corbin, 1998, p. 102). Here, the concepts were seen to be categories or phenomena that were derived from the data itself. Through this process of identifying categories and phenomena, two main layers came through that led the analysis in two directions: examining the content of the discussions and examining the structures of participation. The content of the discussions was analyzed using the lens of mathematical knowledge for teaching (Ball et al. 2008). We began this analysis by reading the discussion threads. Then, we interpreted each individual contribution by identifying the mathematical knowledge for teaching involved and in relation with other contributions within the thread. Then, we examined the participation within the thread according to the components, mutual engagement, joint enterprise, and shared repertoire of the community of practice (Wenger, 1998). For each component, different themes emerged. In the results section, we will present the mobilization of mathematical knowledge for teaching by our participants in regards to their participation in a community of practice. Our participants chose to contribute to the topics: Introduction, 
Random, Mathematics Questions, About Teaching, Share and Open Mic. However, we did not find this information relevant in regards to our analysis on the knowledge shown, although we think it might have inspired our participants to post a contribution. In our discussion, we conducted a cross analysis of our findings using DeBlois and Squalli's (2002) framework. For each component of the community of practice, we looked at the domains of mathematical knowledge for teaching that emerged from our participants. Finally, we identified the epistemological stances suggested by the findings.

\section{Findings}

\subsection{Mutual Engagement}

Mutual engagement of our participants seemed to be in the form of short dialogues. Our participants' interactions were mainly question and answer communications. Some participants also shared their feelings about being in field experience, yet shared little about mathematics specifically. From our collected data, there were two different themes that emerged: the absence of mathematics talk revolving around either common content knowledge or specialized content knowledge, and the prevalence of teaching talk. There was a clear lack of any "pure" mathematics talk in the online discussion. This observation stood out most prominently in the online discussions that centered on how to teach particular mathematical content. Those discussions related to teaching mathematical concepts did not include any detail about the conceptual understanding of those particular concepts.

\section{Boston Cream, 7 May 2009 21:35:}

Hello! I'm introducing Area on Monday for my grade three class and my supervisor will be there evaluating me. I was wonder [sic] if anyone had any interesting ways in which I can introduce this topic. Thanks!

\section{Cinnamon Bun, 8 May 2009 18:00:}

Maybe you could use the area of your classroom like we did in math lab. Hopefully you have good measuring manipulative [sic] to measure the floor. You could first use informal measuring unit such as cut out giant's feet then use formal measuring unit [sic] such a metre stick.

As illustrated in the thread presented, Cinnamon Bun's comment makes reference to teaching area, but does not mention what area is: "maybe you can use the area of the classroom". Furthermore, Cinnamon Bun presents a suggestion to teach area but does not elaborate at all on what Boston Cream would do with the tools that are suggested (giant cut-out feet and a metre stick), thereby emphasizing an absence of mathematical content in the dialogue. Including how one may use the metre stick and cut-out feet may have provided more of an indication as to the nature of the concept of area. As such, there is no evidence of either Common Content Knowledge (CCK) or Specialized Content Knowledge (SCK) in this particular exchange. This was a consistent phenomenon throughout the online forum threads, where dialogue did not include specific mention of the subject of mathematics. As the context of the online discussions focused on lesson planning and preparation, the absence of discussion of content itself is a noteworthy observation. Although this may be interpreted to be the result of participants having a strong knowledge base of mathematics, other data sources (i.e., the reflective assignments) did not support this idea. Also, the data collection instruments were not designed to measure levels of knowledge, but rather to allow us to examine and understand the content and contexts of our participants' discussions.

Seeking out teaching ideas was the most common "problem" presented in the online discussions. In this excerpt from another thread, Date Square is seeking out a means by which to teach "multiplication in expanded form".

\section{Date Square, 30 April 2009 21:05:}

I am set to teach the lesson next week to a group of grade 4 students about how to multiply using expanded form. They are just now being introduced to multiplication using 2 digit numbers. [...] I was wondering if anyone had any ideas about interesting ways to approach this topic with the class.

Similar to what was seen in the previous discussion thread, there is some evidence that our participants' mathematical knowledge for teaching is limited, as evidenced by the need to ask this particular question. However, what is striking as this thread unfolds is that Date Square is able to present a fairly solid understanding of what multiplying in expanded form looks like.

\section{Date Square, 6 May 2009 21:35:}

$54 \times 3=$ 


$$
\begin{aligned}
& 5 \text { tens }+4 \text { ones } \times 3= \\
& 15 \text { tens }+12 \text { ones }= \\
& 16 \text { tens }+2 \text { ones }= \\
& 1 \text { hundred }+6 \text { tens }+2 \text { ones }=162
\end{aligned}
$$

I know this seems like an odd way to multiply... but it gets around the "double digit" issue some new learners have, as it breaks the equation up into tens and ones... then the students have to "regroup" and add to get the answer.

While Date Square may be demonstrating some knowledge of the mathematical content relevant to this discussion thread, the subsequent explanation of why this method of multiplication is helpful in learning multi-digit multiplication, making specific reference to a common student difficulty, makes this comment stand out. We see evidence of KCT, as well as Knowledge of Content and Students (KCS) (Ball et al., 2008) in this discussion entry, as Date Square has successfully intertwined an understanding of how to teach a particular mathematical concept with how that relates to student learning.

Placing students at the center of one's teaching was evident in our participants' discussions. There appeared to be an understanding of the importance of presenting material in an accessible way that appeals to students. This was seen through the use of particular adjectives in queries for teaching ideas.

\section{Date Square, 30 April 2009 21:05:}

I was wondering if anyone had any ideas about interesting ways to approach this topic with the class.

\section{Boston Cream, 7 May 2009 21:35:}

I was wonder [sic] if anyone had any interesting ways in which I can introduce this topic.

Making mathematics "interesting" is seen here as a form of KCS, as participants are seeking to present relevant mathematical content with a fun and engaging activity for students. That is, study participants seem concerned with both knowing students and what they will find interesting, as well as how this can be related to mathematics. The need to make mathematics interesting or fun came out clearly in the reflective assignments, as well, and accordingly is seen as an important aspect of our participants' collective identity.

The online discussions revealed community formation through the mutually developed mode of discourse. What our participants interacted about not only helped us understand how they communicated with each other, but also revealed that the nature of their discourse was dependent on their collective knowledge of teaching mathematics.

\subsection{Joint Enterprise}

Joint Enterprise among our participants seemed to consist of a negotiation of meaning of learning to teach, and therefore shed light on the development of teachers. From our collected data, there were one different theme that emerged: the absence of mathematics talk as either common content knowledge or specialized content knowledge.

\section{NL, 26 April 2009 20:41:}

"Have a great first day, everyone!"

Chocolate Soufflé, 28 April 2009 21:35:

"Thanks it was awesome. It was great to finally be back in the schools!"

Coconut Tart, 5 May 2009 20:23:

"It has been a great one and a half weeks. It goes by so quickly."

\section{Cinnamon Bun, 8 May 2009 18:05:}

"I find that it goes by too quickly also. I wish we had our stages 8 weeks like [another university]. They get more hands on experience compared to us where we have lots of lectures/courses to attend ... yuck. Some courses are helpful but I believe you only really learn what it is to be a teacher when you are actually in the classroom learning from the students and the cooperative teacher [sic] Note 1"

Corn Bread, 9 May 2009 00:30: 
"It is such a wonderful feeling to be in the elementary school classroom. All semester long, we learn theory, and finally, we are given the chance to put theory into practice: It's almost as if everything is coming to life. Every time I teach, I am constantly reassured that this is my profession."

The discussion thread presented above illustrates how discussions brought out the notion of learning to teach. Our participants readily referenced their identity as university students taking courses as part of their path towards learning how to teach. In the content brought forth by our participants, there is no evidence of discussion of mathematical content, and the focus of discussions is directed elsewhere. As illustrated, some threads excluded any discussion of mathematics (or teaching) and focused entirely on participants' role as university students. As Chocolate Soufflé, Coconut Tart, Cinnamon Bun, and Corn Bread reveal, our participants were navigating through their own university courses in a teacher education program, and into a cooperating teacher's classroom. Although Pedagogical Content Knowledge (PCK) (Ball et al., 2008) entails both having and using knowledge of teaching, the notion of learning how to teach is seen as a developing form of PCK. The "learning to teach" theme is presented in two ways: a preference for learning in an elementary school classroom, yet at the same time, the acknowledgement of what still needs to be learned.

\section{Coconut Tart, 5 May 2009 20:23:}

I was very frustrated at the beginning of my Stage because the students are in exams as well as there is very little time to teach due to the other classes such as art, gym, music as well as science and a special project that has to be done by the end of May. I wanted to be able to teach lessons, but I didn't know what to teach because my CT told me that she had stopped teaching. Things changed today when we got a hold of the Math exam, and now we as a team are working together to prepare the students. I am now really really enjoying my stage.

In this first of our participants' field experiences, participants readily described the learning that they each still had to do on their respective paths towards becoming teachers. These descriptions were explicit and pointed to the unique position our participants found themselves in. That is, as our participants moved from their own university classes to an elementary school classroom, their comments on their learning trajectories (Wenger, 1998) were often concerned directly with the hit-or-miss reality of their field experience, which may or may not have put pre-service teachers into the type of environment they desired. As such, our participants related the potential for learning in the field experience to their particular classroom placement and cooperating teacher.

\section{Butter Pecan, 29 April 2009 15:37:}

It is a little less intimidating teaching to only a few students, but at the same time they are the students with learning disabilities and behaviour issues so it's going to be a challenge for me to really reach them.

\section{Graham Crackers, 6 May 2009 20:19:}

I'm teaching grade 1 and realized just how exhausting it can be to keep up with these active, young kids!

\section{Jaw Breaker, 28 April 2009 17:37:}

At first I was upset that I would be in a media class ... but my teacher is amazing ... I am learning a lot about media which is great because I really need it!

The desire to learn in the field experience coupled with the desire to be in the elementary classrooms (over being in their university classes) is evident in the preceding passages. The urgency to "teach lessons" and work with students are opportunities that our participants sought.

How our participants chose to interact with each other relates to what they chose to interact about. That these two aspects of the participants' communication were so intertwined with one another is indicative of what Wenger (1998) deemed to be the complexity of how community members develop a means to engage in their practice. In this sense, how and with what our participants engaged provided insight into the shared identity that they formed.

\subsection{Shared Repertoire}

Two themes emerged from the shared repertoire of our participants: the shared resources and the use of resources for information sharing. Our participants asked for and responded to requests for shared resources to support them in their field experience. They also sought resources for planning and preparing students for exams. The shared repertoire, therefore, focused on knowledge of content and curriculum. 


\section{Coconut Tart, 5 May 2009 20:18:}

I am in the same position and had a chance to look at the exam today. You may want to teach changing fractions into \% as well as probability. I am lucky my CT showed me some of the situational problems from the past years and I am using those to review for the math exam. Hope that helps.

The problem highlighted in this thread is how to prepare students for a provincial exam without having seen the exam itself. There is evidence here of the limited view of resources that may help one develop an understanding of the curriculum and how to teach relevant content. Accordingly, this is viewed as a discussion related to Knowledge of Content and Curriculum (KCC). Our participants revealed limited knowledge of curriculum in this particular discussion. The issue of how to prepare students for the provincial exam was presented in light of having not yet seen the provincial exam. In other words, participants seemed to believe that the only way in which one can know how to prepare for an exam is to see the exam itself.

\section{Baked Alaska, 30 April 2009 14:51:}

I have yet to see the exam and only know that fractions and measurement will be on it. Can anyone give me any tips?

Knowledge of curriculum is directly related to knowing what a provincial exam will cover. A limited knowledge of curriculum is further evidenced by the resolution to this discussion, where Coconut Tart simply lists some topics that Baked Alaska may want to cover, stating that the exam itself revealed these nuggets of information.

How our participants mined the resources available to them brought forth an understanding of how they worked with the materials available to them. In a discussion thread presented previously, we saw Date Square describe a situation in which they were preparing a lesson on multiplying in expanded form. Like Coconut Tart, Date Square had a resource available for use; in this case, a textbook. The problem presented in Date Square's case was, however, a lack of information in the textbook.

\section{Date Square, 30 April 2009 21:05:}

The textbook they use has only 2 pages on this topic, one and a half of which is an example so I do not have much to fall back on there. I was wondering if anyone had any ideas about interesting ways to approach this topic with the class.

Similar to the discussion involving Coconut Tart and their perception of the provincial exam, Date Square sees the textbook as the sole source of information from which to draw in preparing for a lesson. The provincial exam and mathematics textbooks are viewed as artifacts from which our participants can acquire and pass along knowledge of the curriculum to one another. Furthermore, these resources are revealed as the only artifacts used by our participants. As Coconut Tart alluded to in the discussion above, seeing the provincial exam itself is the only way in which to prepare for the exam. Date Square is similarly stuck when the textbook is seen to only provide one example of how to multiply in expanded form.

The planning resources our participants used in their work (i.e., provincial exams and textbooks) are resources used by the larger teaching community. In this sense, these resources are seen as shared between our participants (as individuals who are learning to teach) and practicing teachers. As our participants learned to use these resources, however, they revealed a limited view of knowledge of curriculum, as they experienced difficulty in understanding what information these resources could provide. The disjunction between what information these resources provide and how our participants used the information begins to highlight the dual-position of our participants: a university student learning to become a teacher, and a teacher in an elementary classroom.

\section{Discussion}

\subsection{Emerging Stance within the Community of Practice}

What our participants dialogued about revealed only certain aspects of mathematical knowledge for teaching (Ball et al., 2008) they may have. The fact that participants did not discuss particular aspects of this unique class of knowledge does not mean that they don't have it. Our findings show that some aspects of knowledge did not emerge from the online discussions. In this study, our participants focused mainly on aspects of pedagogy. This finding is consistent with Brown et al.'s (1999) notion that pre-service teachers must first address pedagogical concerns before they can examine mathematical content itself. The mathematical knowledge for teaching that was highlighted in our data also draws attention to the governing epistemological stances (DeBlois \& Squalli, 2002) of our participants. These stances were seen through the emphasis on pedagogical content knowledge and absence of discussion of subject matter knowledge. The depth of knowledge used was intricately related to the stage of each participant in their development from student to teacher, which was highlighted within all aspects 
of their discourse. This ultimately proved to be the very essence of how our participants understood themselves. Table 1 summarizes how our participants revealed their epistemological stance through their use of mathematical knowledge for teaching.

Table 1. Epistemological stances revealed through the use of mathematical knowledge for teaching

\begin{tabular}{lcc}
\hline Community of practice & Domains of mathematical knowledge for \\
teaching & Epistemological stance
\end{tabular}

\begin{tabular}{|c|c|c|}
\hline Mutual engagement & $\begin{array}{l}\text { SMK: Absence of math talk (as absence of CCK } \\
\text { and SCK) }\end{array}$ & $\begin{array}{l}\text { University student } \\
\text { - An absence of CCK and SCK with focus on KCT } \\
\text { and KCS }\end{array}$ \\
\hline & PCK: Prevalence of teacher talk (as KCT and KCS) & $\begin{array}{l}\text { - KCT and KCS motivated by concerns over an } \\
\text { evaluation and visit from supervisor }\end{array}$ \\
\hline Joint enterprise & $\begin{array}{l}\text { SMK: Absence of math talk (as absence of CCK } \\
\text { and SCK) } \\
\text { PCK: Learning to teach (as KCT and KCS) }\end{array}$ & $\begin{array}{l}\text { Transitioning from university student to teacher } \\
\text { - Working as teachers with university student role } \\
\text { affecting their work }\end{array}$ \\
\hline Shared repertoire & $\begin{array}{l}\text { SMK: Listing of mathematical topics (fractions, } \\
\text { percent and probability) } \\
\text { PCK: Preparing for lessons and standardized exams } \\
\text { (as KCC) } \\
\text { (use of common resources) }\end{array}$ & $\begin{array}{l}\text { Transitioning from university student to teacher } \\
\text { - Learning to work with, use and understand } \\
\text { teacher resources } \\
\text { - Use of teacher resources highlights university } \\
\text { student trying to be a teacher }\end{array}$ \\
\hline
\end{tabular}

Our participants' discussions of teaching mathematics lacked mention of mathematics as either common content knowledge or specialized content knowledge. The effect of this was an emphasis on teacher talk: seeking ways in which to teach mathematics. The talk of teaching mathematics, however, appeared to be motivated by factors that point towards our participants' role as a student in a teacher education program. In particular, we saw mention of successful evaluations in the field experience. For example, one participant's search for teaching ideas was motivated by an impending evaluation: "I'm introducing Area on Monday for our grade three class and our supervisor will be there evaluating me" (Boston Cream). In this sense, the talk of teaching mathematics is a result of not just needing help with teaching but with serving the requirement of a formal evaluation in a teacher-education program. This emphasis in our participants' discussion puts a spotlight on their university-student epistemological stance, as the underlying theme of their discourse was the nature of their learning environment.

One aspect of participants' discussion of their learning environment involved their recognition of the need to work in someone else's classroom. Although such discussion was marked by frustration with having to work with the cooperating teacher, our participants were clearly excited to be "in a classroom". Together, this supports the notion that our participants were learning to become teachers, rather than being teachers themselves. This is significant as our participants were allowing change in their role as a student to come through in their role as a teacher. In other words, although presented with a learning environment that would allow them to be a teacher, our participants revealed a dominant dependence on their student role. This was seen not just through the focus on their cooperating teacher but also in their elation with the prospect of engaging in practical learning experiences rather than theoretical learning experiences (their university classes).

Generally speaking, the phenomenon of preference for practical experience and teaching is consistent with the "magical" first classroom experiences of a pre-service teacher (Philipp et al., 2002; Philipp et al., 2007), where pre-service teachers are more enthralled by the euphoria of being in a "real" classroom than with discussion of the issues related to teaching. Certainly, a teacher persona comes through in our participants, as they work and learn to be teachers in an elementary classroom. Although the teaching-perspective appears to dominate our 
participants' discussions and may indicate a significant progression from student to teacher, there is reason to believe this is not the case. With the clear absence of mathematical talk, we see a gap in how our participants used their mathematical knowledge for teaching.

Teaching mathematics, after all, requires that the teacher understands not only the mathematical content, but how students may perceive and learn that mathematical content, as well (Ball et al., 2008). Analysis of online discussions only found one instance in which an individual (Date Square) referred to their students when seeking teaching ideas for a mathematical concept. The majority of our participants simply asked for general teaching ideas and activities without describing the context of the classroom or the students in that classroom. Thus, although our participants spoke frequently about how to teach, their mode of questioning revealed a superficial view of teaching. There was a consistent view from our participants that generating teaching ideas did not require one to consider to whom the lesson would be delivered. This view was also informed by the reflective assignments, where a high number of individuals in the participant pool pledged to devote their practice to making mathematics fun and interesting. This pledge was often hinged on participants' own negative experiences learning mathematics in elementary school. In accordance with Brown et al. (1999), elementary teachers in training are moving from their role as a student in a teacher-training program to a teacher in a school, a movement that is affected by the teacher's own experience in elementary school. However, in expressing their desire to make mathematics "fun" and "interesting", participants made no mention of the students. For this reason, it is possible that our participants are not in the phase of development where one thinks about both pedagogy and students (Brown et al., 1999), but are perhaps just entering this phase.

This notion that our participants are navigating between student and teacher was further emphasized as they engaged in the work of a teacher. In preparing for lessons, our participants took to sharing information with each other by making use of resources, such as textbooks and provincial exams. How our participants used these materials was consistent with the observed dominant perspective of student over that of teacher in the majority of our participants. That is, the use of the materials was somewhat basic in nature and suggested an incomplete understanding of what information certain resources could provide. The resources our participants found themselves using were seen as black and white with certain absolute information, perhaps even the sole answer. For example, textbooks were seen to be the only source of curriculum content, rather than a resource that presents a particular interpretation of the curriculum. Our participants also understood that the only way to prepare their students for the upcoming provincial exam was to first see the exam itself and then teach to the exam. In these ways, our participants' use of curriculum resources was limited. Furthermore, no one referenced the curriculum document itself as a key source of information. These approaches to identifying and using available resources provide evidence of the challenges of navigating new territory: that of the working teacher. These attempts to work as a teacher call attention to certain significant features of participants and the identity they are working towards.

The provincial exam and textbooks are resources commonly used by practicing teachers in their everyday work. Our participants' use of textbooks and the provincial exams points to this community's proximity to the greater community of practicing teachers. Furthermore, our participants' use of these shared resources reveals an overlap of this online community to the greater community of practicing teachers. Figure 1 provides a depiction of our participants' proximity to the community of teachers as they attempt to move into this community themselves.

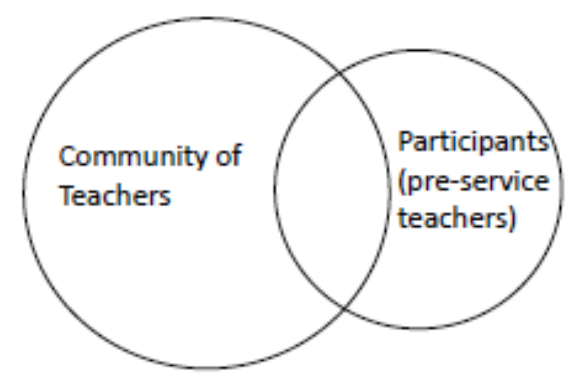

Figure 1. Participants' proximity to the community of teachers as they attempt to move into this community themselves 
The proximity of each group in the diagram is purposeful and showcases that there are individuals who may lie distinctly in one of the two circles and those that may lie in the overlap of the two. In this study, there were individuals within the community who were much closer to the student end of the development continuum. The overlap of the circles represents those pre-service teachers who were further along the continuum, and who possessed and used mathematical knowledge for teaching in a similar way to that of a practicing, seasoned teacher. Thus, the overlap is representative of the student-teacher perspective, that of the intermediary role between student and teacher.

The online discussions highlighted the dual roles that our participants are engaged in: that of a university student learning to become a teacher, and that of a teacher in an elementary classroom. That our participants are straddled between two different roles was further emphasized by their discussions, which revealed how they worked in both these roles. Although not evident from the online data, a third epistemological stance, that of each participant's own elementary school experience (DeBlois \& Squalli, 2002), both affected how our participants identified with each other and revealed a dichotomy common to the experience of the pre-service teacher. Development from student to teacher was tied not only to how our participants understood their identity, but also determined how they engaged with each other and how they shared and disseminated information. Understanding how and what our participants engaged in within their online discussions revealed how they work with their mathematical knowledge for teaching. It also shed some lights on how our participants as individuals who are developing from a student into a professional.

\subsection{Limits of This Study}

The online community was open for six weeks while pre-service teachers were on a three-week field experience. This was very short time in terms of establishing a community of practice, as the community of practice was only just emerging. Contributions to the discussions in this online venue were made by 23 individuals. However, there were varying degrees of participation in the online community: from active contributors to those that logged-in frequently without making any postings. This level of participation, which was dependent upon the number of contributing participants and how often the online community was used, replicates the participation levels of other online venues used in both educational and non-educational settings. In studying online teacher communities, Selwyn (2000) observed similar heavy use by only a small portion of participants, attributing the overall lack of activity to members feeling stronger ties to another face-to-face community. This may have been a contributing factor in the present study, as our participants attended a weekly seminar course during their three-week field experience. This seminar course allowed participants some face-to-face interaction with each other, in which they had the opportunity to share their thoughts and reflections on their respective field experiences. The fact that our participants were able to connect with each other and other pre-service teachers not involved this study in a face-to-face meeting could have restricted the dialogue in the online discussion forum. For example, if support and advice was solicited in the seminar course, any one of our participants may not have felt it necessary to log-in and pose the same question to the members of the online community. Accordingly, one of the contributing factors to the success of online discussions is that membership be comprised of competent individuals with a shared work interest who find it difficult to meet face-to-face (Riel \& Levin, 1990). Discussions of the effect of such face-to-face interactions in the research literature, however, do no present a consistent picture. While some have found face-to-face interactions to decrease participation levels online (Stephens \& Hartmann, 2004), others have attributed high online participation levels to the establishment of such face-to-face relationships, arguing that these relationships serve to increase trust in online spaces (Hough et al., 2004). In our case, the face-to-face connection our participants found in their seminar course may not have been the only factor affecting the use of the online forum. It is possible that participants' seminar course emphasized and enabled participants to retain their student-perspective. This student-perspective had an effect on the online community, as the manner in which participants interpreted their surroundings was done predominantly from the point-of-view of a student, rather than that of a teacher.

Finally, as individuals learning to be teachers, our participants used the online community as a means to collaborate with one another, to share and to develop a repertoire of teaching ideas. It is worth noting that the moderator of the online community could have played a more prominent role in eliciting and prompting participant answers.

As mentioned earlier, the mathematical knowledge for teaching that emerged from this study was contextualized, dependent not only on what pre-service teachers had to teach, but on which grade they were teaching, as well. 


\section{Conclusion}

The progression from student to professional intricately weaved together how our participants interacted in the online discussion with the knowledge about which they interacted. This progression also affected how our participants developed and shared repertoires, revealing their place in the larger teaching community. In this study, mathematical knowledge for teaching was examined in parallel with students' development on the path towards becoming teachers.

There is a need to develop mathematics teachers who understand both the subject matter and pedagogical knowledge of mathematics (Ball et al., 2005). This pilot study suggested that some pre-service teachers see their two main learning environments, the university classroom and the school classroom, as distinct contexts. Furthermore, this study suggested that pre-service teachers bring much of their university student persona to the school classroom, and consequently, find it difficult to engage in teaching conversations about mathematics that are both generative (Philipp et al., 2007) and that promote professional growth. Ultimately, it was the manner in which pre-service teachers used their mathematical knowledge for teaching that revealed insight into their development as mathematics teachers. We need to caution that the display of a particular mathematical knowledge for teaching by a given pre-service teacher does not mean that they are lacking other knowledge for teaching mathematics.

We believe that this study provides significant insight into both pre-service teachers and what teacher-education programs need to know, in order to deliver effective teaching programs. By understanding the student population, and knowing what lenses they use to understand and make sense of their learning, teacher educators can narrow the gap between their expectations for their students' learning and what their students can actually gain from their teacher-education program.

\section{Acknowledgements}

We want to acknowledge the support of the Social Sciences and Humanities Research Council of Canada.

\section{References}

Ball, D. L., Hill, H. C., \& Bass, H. (2005). Knowing mathematics for teaching: Who knows mathematics well enough to teach third grade, and how can we decide? American Educator, 29(3), 14-17, 20-22, $43-46$.

Ball, D. L., Thames, M. H., \& Phelps, G. (2008). Content knowledge for teaching: What makes it special? Journal of Teacher Education, 59, 389-407. http://dx.doi.org/10.1177/0022487108324554

Brown, T., McNamara, O., Hanley, U., \& Jones, L. (1999). Primary student teachers' understanding of mathematics and its teaching. British Educational Research Journal, 25(3), 299-322. http://dx.doi.org/10.1080/0141192990250303

Chapman, O. (2012). Challenges in mathematics teacher education. Journal of Mathematics Teacher Education, 15(4), 263-270. http://dx.doi.org/10.1007/s10857-012-9223-2

Charalambos, C., Philippou, G., \& Kyriakides, L. (2002). Towards understanding teachers' philosophical beliefs about mathematics. Paper presented at the International Group for the Psychology of Mathematics Education (PME), Norwich UK.

Cooney, T. J., Shealy, B. E., \& Arvold, B. (1998). Conceptualizing belief structures of preservice secondary mathematics teachers. Journal for Research in Mathematics Education, 29(3), 306-333. http://dx.doi.org/10.2307/749792

DeBlois, L., \& Squalli, H. (2002). Implication de l'analyse de productions d'élèves dans la formation des maitres $\mathrm{du}$ primaire (Implication of the analysis of student productions in the formation of primary teachers). Educational Studies in Mathematics, 50(2), 213-238. http://dx.doi.org/10.1023/A:1021116014594

Ernest, P. (2000). Teaching and learning mathematics. In V. Koshy, P. Ernest, \& R. Casey (Eds.), Mathematics for primary teachers. London, UK: Routledge.

Hiebert, J., Gallimore, R., \& Stigler, J. W. (2002). A knowledge base for the teaching profession: What would it look like and how can we get one? Educational Researcher, 31(5), 3-15. http://dx.doi.org/10.3102/0013189X031005003

Hill, H. C., Ball, D. L., \& Schilling, S. G. (2008). Unpacking pedagogical content knowledge: Conceptualizing and measuring teachers' topic-specific knowledge of students. Journal for Research in Mathematics Education, 39(4), 372-400. 
Hough, B. W., Smithey, M. W., \& Evertson, C. M. (2004). Using computer-mediated communication to create virtual communities of practice for intern teachers. Journal of Technology and Teacher Education, 12(3), 361-386.

Philipp, R. A. et al. (2007). Effects of early field experiences on the mathematical content knowledge and beliefs of prospective elementary school teachers: An experimental study. Journal for Research in Mathematics Education, 38(5), 438-476.

Philipp, R. A. et al. (2002). The role of a children's mathematical thinking experience in the preparation of prospective elementary school teachers. International Journal of Educational Research, 37, 195-210. http://dx.doi.org/10.1016/S0883-0355(02)00060-5

Riel, M. M., \& Levin, J. A. (1990). Building electronic communities: Success and failure in computer networking. Instructional Science, 19, 145-169. http://dx.doi.org/10.1007/BF00120700

Savard, A. (2014). Transition between university students to teachers: Practice in the middle. Canadian Journal of Science, Mathematics and Technology Education, 14(4), 359-370. http://dx.doi.org/10.1080/14926156.2014.964882

Schlager, M., Fusco, J., \& Schank, P. (1998). Cornerstones for an on-line community of education professionals. Technology and Society Magazine, IEEE, 17(4), 15-21. http://dx.doi.org/10.1109/44.735857

Schommer, M. (1994). Synthesising epistemological belief of research: Tentative understandings and $\begin{array}{llll}\text { provocative confusions. Educational Psychology Review, 6, 293-319. } & \text {. }\end{array}$ http://dx.doi.org/10.1007/BF02213418

Selwyn, N. (2000). Creating a "connected" community? Teachers' use of an electronic discussion group. Teachers College Record, 102, 750-778. http://dx.doi.org/10.1111/0161-4681.00076

Shulman, L. S. (1987). Knowledge and teaching: Foundations of the new reform. Harvard Educational review, 57(1), 1-22. http://dx.doi.org/10.17763/haer.57.1.j463w79r56455411

Strauss, A., \& Corbin, J. (1998). Basics of qualitative research-Techniques and procedures for developing grounded theory (2nd ed.). Thousand Oaks, CA: SAGE Publications.

Wenger, E. (1998). Communities of practice. Cambridge, Cambridge University Press. http://dx.doi.org/10.1017/cbo9780511803932

\section{Note}

Note 1. It is believed Cinnamon Bun meant to say "cooperating teacher", who is the classroom teacher that agrees to work with a pre-service teacher in his/her classroom for the duration of the field experience.

\section{Copyrights}

Copyright for this article is retained by the author(s), with first publication rights granted to the journal.

This is an open-access article distributed under the terms and conditions of the Creative Commons Attribution license (http://creativecommons.org/licenses/by/4.0/). 